\title{
Antibodies to Lipopolysaccharides after Immunization of Humans with the Rough Mutant Escherichia coli J5
}

\author{
J. D. Baumgartner, D. Heumann, T. Calandra, \\ and M. P. Glauser
}

Division of Infectious Diseases, Department of Internal Medicine,
Centre Hospitalier Universitaire Vaudois, Lausanne, Switzerland

To investigate whether immunization with Escherichia coli $\mathrm{J} 5$ boiled cells induces antibodies directed at deep core structures, antibodies against J5 lipopolysaccharide (LPS), Re LPS, and lipid $A$ were measured in the serum of 70 volunteers before and 2 weeks after immunization. To improve the sensitivity and the specificity of ELISA, complexes of core LPS with high-density lipoproteins were used instead of free core LPS as antigens. A median three-fold increase in antibodies directed against J5 LPS was observed, but no significant increase in the antibodies against Re LPS or lipid A was found. Since J5 antiserum did not react with several smooth LPS or with Re LPS and lipid A, cross-reactivity could not be demonstrated. Thus, immunization of volunteers with $E$. coli $J 5$ produced a modest specific antibody response against J5 LPS. The mechanism of protection previously observed with J5 antiserum remains unclear.

Two clinical trials have suggested that human serum from volunteers immunized with the rough mutant Escherichia coli J5 (J5 antiserum) is effective as an adjunct in the treatment [1] or prevention [2] of gram-negative shock. However, the mechanism of protection against gram-negative septic shock afforded by $\mathrm{J} 5$ antiserum remains unknown. Rough mutants of gram-negative bacilli expose on their surface various parts of the core region of the lipopolysaccharide (LPS) that are hidden on smooth bacteria by the $\mathbf{O}$-side chains and are therefore poorly accessible to immunologic reactions. Since the core LPS is relatively conserved phylogenetically, a working hypothesis is that anti-core LPS antibodies may cross-react with various gram-negative bacteria and possibly be protective against a wide range of gram-negative bacteria. However, the outcome of patients correlated weakly [1] or not at all (unpublished data) with the levels of J5 LPS antibodies measured in the sera administered.

J5 LPS is a complex molecule composed of core saccharides (heptose, glucose, $\mathrm{N}$-acetylglucosamine, and 3-deoxyD-manno-2-octulosonate [KDO]), of phosphate, ethanolamine, and of the toxic lipid A [3]. Immunization with J5 vaccine might therefore induce a mixture of antibodies against various epitopes of J5 LPS. A hypothesis raised to explain the lack of correlation between protection and levels of J5 LPS antibodies was that only antibodies directed to the immunodominant core sugars are detected when measuring J5 LPS

Received 5 July 1989; revised 18 October 1990.

All study participants gave informed consent.

Grant support: Fonds National Suisse de la Recherche Scientifique (3.825$0.86,32-25550.88$ ).

Reprints or correspondence: Dr. J. D. Baumgartner, Division of Infectious Diseases, CHUV, CH-1011 Lausanne, Switzerland.

The Journal of Infectious Diseases 1991;163:769-772

(C) 1991 by The University of Chicago. All rights reserved.

0022-1899/91/6304-0015\$01.00 antibodies with an ELISA or with an indirect hemagglutination test. If the postulated cross-protective antibodies are directed at deeper core structures, such as lipid A or the lipid A-KDO region, they may remain undetected when the whole J5 LPS molecule is used as antigen in serologic tests, because these deeper structures may be hidden by the outermost core sugars.

To investigate this hypothesis, we measured by ELISA the antibody response to lipid A and Re LPS (composed of lipid $A$ and $\mathrm{KDO}$ ) after 70 healthy volunteers were vaccinated with Escherichia coli J5. Core LPS, especially Re LPS and lipid A, are hydrophobic structures with limited solubility and selfaggregating properties. They are difficult to use as antigens in ELISA because the coating of the plates may be poor and because nonspecific sticking of immunoglobulins to hydrophobic structures may be observed [4]. We have noted that complexing LPS to high-density lipoproteins (HDL), a natural carrier of LPS, modified the physicochemical state of core LPS and that use of HDL-LPS complexes to coat ELISA plates increased both the sensitivity and the specificity of the test compared with coating with free-core LPS [4].

In the present study, we used complexes of LPS with HDL instead of free LPS as coating antigens [4]. To study whether $\mathrm{J} 5$ vaccine produces a polyclonal antibody increase, we also measured the levels of antibody directed against LPS from E. coli O111 (O111 LPS) and against a mixture of LPS from seven different, smooth gram-negative strains and total IgG and IgM levels.

\section{Materials and Methods}

Immunization of volunteers. The procedure was performed as previously described [1]. E. coli J5 vaccine (provided by E. J. Ziegler, San Diego) was prepared from stationary-phase $E$. coli J5 bacterial cells grown in trypticase soy broth, harvested by centrifugation, washed three times in sterile $0.15 M$ sodium chloride, boiled for 
$2.5 \mathrm{~h}$, adjusted to $5 \times 10^{9}$ bacteria/ml, and conserved with $5 \mathrm{~g} / 1$ of phenol. Healthy volunteers were immunized subcutaneously with two 1-ml injections of $E$. coli J5 vaccine simultaneously in two separate sites and with two more 1-ml injections $48 \mathrm{~h}$ later. Plasma samples were collected before and 2 weeks after the first injections. The plasma were used during a study of prevention of gram-negative septic shock in high-risk surgical patients [2], and aliquots were kept at $-70^{\circ} \mathrm{C}$ for antibody determinations.

LPS. LPS from $E$. coli O111:B4 (O111 LPS,) $E$. coli O26, $E$. coli 0127 , Salmonella minnesota S128, Salmonella enteritidis, Salmonella typhimurium, and Serratia marcescens were obtained from Sigma Chemical (St. Louis). LPS from $E$. coli J5 mutant (J5 LPS), LPS from $S$. minnesota R595 mutant (R595 LPS), and lipid A from S. minnesota R595 mutant (R595 lipid A) were obtained from Ribi Immunochem Research (Hamilton, MT). LPS from $E$. coli D3 $1 \mathrm{~m} 4$ (D31m4 LPS) (an Re-type rough mutant) and the lipid A extracted from it (D3 $1 \mathrm{~m} 4$ lipid A) were obtained from List Biological Laboratories (Campbell, CA). Lyophilized LPS were reconstituted in pyrogen-free water to a concentration of $1 \mathrm{mg} / \mathrm{ml}$. Triethylamine $(0.5 \% \mathrm{vol} / \mathrm{vol})$ was added for Re LPS and lipid A.

Determination of antibody levels by ELISA. Complexes of LPS with HDL were used instead of free LPS as coating antigens (see [4]). Controls with HDL alone were included and background values from these wells were subtracted from the readings. Hyperimmune rabbit antisera specific for $E$. coli $0111, \mathrm{~J} 5, \mathrm{D} 31 \mathrm{~m} 4 \mathrm{LPS}, S$. minnesota R595 LPS, and for lipid A extracted both from $S$. minnesota $\mathrm{R} 595$ and from $E$. coli D31m4 were used to demonstrate the adequate presence of antigens on the plates. The assay was standardized with immunopurified human anti-J5 LPS IgG or IgM antibodies prepared as described [4]. A standard curve was established with the immunopurified antibodies for the determination of the levels of antibodies in the test samples. For the purpose of this study, the same standard curve was used to estimate the concentrations of all antiLPS antibodies measured simultaneously with J5 LPS antibodies. The sensitivity of the assay was $0.5 \mu \mathrm{g} / \mathrm{ml}$ for IgG or IgM antibodies. For antibodies to $E$. coli D31m4 LPS and lipid A, which were assayed later, the results were reported as arbitrary units (AU; optical densities $x$ dilutions).

IgG and IgM serum levels. Total IgG and IgM serum levels were measured by standard methods using a Behring nephelometer analyzer (Hoechst-Behring).

Statistical methods. Antibody levels before and after immunization were compared by the nonparametric Wilcoxon paired-sample test.

\section{Results}

Antibodies to J5 LPS. Of the 70 volunteers before immunization, $60 \%$ and $96 \%$ had detectable levels of IgG and IgM antibodies, respectively, against J5 LPS. These values increased to $86 \%$ and $99 \%$ after vaccination with $E$. coli $\mathrm{J} 5$. The median increase in the levels of antibodies directed to J5 LPS was 3-fold for IgG and a 3.25-fold for IgM (table 1). This slight increase contrasted with the several hundredfold increase observed in rabbits immunized intravenously: titers usually increased from 1:100-1:200 before immunization to 1:25,6001:102,400 after immunization with boiled bacterial cells.
Table 1. Antibody levels in 70 volunteers immunized with Escherichia coli J5.

\begin{tabular}{|c|c|c|c|c|c|c|}
\hline \multirow[b]{2}{*}{$\begin{array}{l}\text { Antibody, } \\
\text { antigen* }\end{array}$} & \multicolumn{6}{|c|}{ Median levels of anti-LPS antibody $(\mu \mathrm{g} / \mathrm{ml})$} \\
\hline & & $\begin{array}{l}\text { Before } \\
\text { munization } \\
\text { (range) }\end{array}$ & & $\begin{array}{l}\text { After } \\
\text { Imunization } \\
\text { (range) }\end{array}$ & $\begin{array}{c}\text { Fold } \\
\text { increase }\end{array}$ & $P$ \\
\hline \multicolumn{7}{|l|}{$\lg (\mathbf{i}$} \\
\hline J5 LPS & 4 & $(<0.5-87)$ & 13 & $(<0.5-251)$ & 3.25 & $<10^{-6}$ \\
\hline R595 LPS & 5 & $(<0.5-116)$ & 5 & $(<0.5-135)$ & 1 & NS \\
\hline R595 lipid A & 3 & $(<0.5-41)$ & 3 & $(<0.5-69)$ & 1 & NS \\
\hline O111 LPS & $<0.5$ & $(<0.5-30)$ & $<0.5$ & $5(<0.5-50)$ & 1 & NS \\
\hline Smooth LPS $\dagger$ & 21 & $(<0.5-140)$ & 26 & $(<0.5-117)$ & 1.24 & NS \\
\hline \multicolumn{7}{|l|}{ IgM } \\
\hline J5 LPS & 3 & $(<0.5-33)$ & 9 & $(<0.5-53)$ & 3 & $<10^{-6}$ \\
\hline R595 LPS & 1 & $(<0.5-8)$ & 1 & $(<0.5-5)$ & 1 & NS \\
\hline R595 lipid A & $<0.5$ & $(<0.5-3)$ & $<0.5$ & $(<0.5-2)$ & 1 & NS \\
\hline O111 LPS & 1 & $(<0.5-14)$ & 1 & $(<0.5-14)$ & 1 & NS \\
\hline Smooth LPS & 4 & $(<0.5-26)$ & 4 & $(<0.5-27)$ & 1 & NS \\
\hline
\end{tabular}

NOTE. LPS, lipopolysaccharide.

* Complexes of high-density lipoproteins with LPS or lipid A were used to coat plates.

$\dagger$ Mixture of LPS from seven smooth bacterial strains (see text).

Antibodies to Re LPS and to lipid A. Of volunteers before immunization, $67 \%$ and $69 \%$, respectively, had detectable IgG and IgM antibodies against $S$. minnesota Re LPS and 59\% and $16 \%$ against $S$. minnesota lipid A. Overall, these values did not increase significantly after vaccination, and there was no significant increase of the antibody levels in the subgroup of volunteers with detectable preimmune levels (table 1).

Since antigenic and structural differences exist between the core regions of $S$. minnesota and $E$. coli, we measured antibodies against the LPS of a Re mutant of $E$. coli (strain D31m4) and against its lipid $A$ in the sera of 21 volunteers randomly selected from our series. Before immunization with $E$. coli $\mathrm{J} 5$, the median (range) levels were $6 \mathrm{AU}(0-64)$ for IgG and 2 (0-21) for IgM anti-D31m4 LPS antibodies, and $2(0-31)$ and 9 (0-55) AU, respectively, for anti-D31m4 lipid A antibodies. There was no statistically significant increase in any of these antibodies after immunization. In only four volunteers was some increase (less than threefold) in the levels of one or several antibodies observed.

Antibodies to LPS from smooth bacteria and total immunoglobulin levels. No significant increase in specific IgG or IgM antibodies against LPS from $E$. coli 0111 (the parent of the J5 mutant) was observed. A slight increase of the median IgG antibody level against the mixture of LPS from seven smooth bacterial strains (1.24-fold) was not statistically significant and of doubtful biological importance. IgM antibodies directed against the same seven antigens did not increase (table 1).

The total serum IgG or IgM levels were measured in 10 volunteers randomly selected from our group: The mean (SD) IgG serum levels before and after immunization were 9.4 (1.4) 
$\mathrm{g} / 1$ and $9.2(1.1) \mathrm{g} / 1$, and the mean (SD) IgM serum levels were $1.0(.04) \mathrm{g} / 1$ and $1.0(.05) \mathrm{g} / 1$, respectively.

\section{Discussion}

The current knowledge of the protective activity of antibody to endotoxin core was recently reviewed [5]. There is no direct and convincing proof so far that the protection observed with polyclonal antisera to rough mutants in animal experiments [6-8] is due to cross-reactive anti-LPS antibodies (see [9]). The protection reported with some monoclonal antibodies [10-12] needs confirmation [13-15]. In humans, there has been a discrepancy in clinical trials between the protection afforded by $\mathrm{J} 5$ antiserum and the weak or lack of correlation with the levels of J5 LPS antibodies measured in sera administered to patients.

In the present study, we found that immunization of volunteers with $E$. coli $\mathrm{J} 5 \mathrm{did}$ not result in a marked elevation of anti-J5 LPS antibodies, or in an elevation of anti-lipid A, antiRe LPS, or anti-smooth LPS antibodies. This further raises the question of the mechanism of protection afforded by antiJ5 serum or plasma. One possible explanation for this discrepancy is that the antibody responsible for protection has not been accurately measured by the serologic methods used.

Detection of antibodies to the various core LPS is difficult because of the limited solubility and self-aggregating properties of hydrophobic core LPS, which may lead to nonspecific binding of antibodies and to irregular coating of ELISA plates. To avoid these problems, we modified the physicochemical state of core LPS by complexing it to HDL, a natural carrier of HDL in vivo, and used HDL-LPS complexes to coat the plates. This method has been shown to increase the sensitivity and the specificity of the detection of core LPS or lipid $A$ antibodies [4]. In addition, the core region itself shows significant inter- and intraspecies differences in its composition [13], and type-specific antibodies are elicited after immunization with rough mutants. The structures most likely to induce broadly cross-reactive anti-LPS antibodies are the most conserved parts, that is, lipid A or the lipid A-KDO region. Therefore, if lipid A or lipid A-KDO antibodies are a subset of J5 LPS antibodies, their detection might be obscured by the quantitatively predominant type-specific J5 LPS antibodies. Moreover, since LPS in outer membranes is heterogeneous [16], the innermost region of LPS may be exposed at the surface of the whole J5 bacteria, whereas only complete LPS with core sugars may be present in the J5 LPS extracted by chemical methods. Thus, immunization with whole $\mathrm{J} 5$ bacteria would induce core LPS antibodies not detectable when using purified J5 LPS as antigen.

We investigated whether J5 vaccine induced the production of antibodies against lipid $\mathrm{A}$ or the lipid A-KDO region that would not be adequately detected by ELISA using J5 LPS as antigen. We could not detect significant increases of antibodies to two lipid A and two Re LPS extracted both from
$S$. minnesota R595 or from $E$. coli D31m4. Since the use of HDL-LPS complexes instead of free LPS as antigen may mask epitopes of the core LPS, it remains possible that antibodies against these hidden epitopes may be missed. This seems unlikely, however, because monoclonal antibodies directed against well-defined epitopes of core LPS easily recognize their epitopes within HDL complexes [4]. Our results question the role of antibodies to lipid A or to lipid A-KDO as protective factors in $\mathrm{J} 5$ antiserum, although these negative findings must be compared with those of clinical studies (now underway) with anti-lipid A monoclonal antibodies and with purified intravenous immunoglobulins enriched in anti-Re LPS antibodies.

Another possible explanation for the discrepancy between the protection afforded by $\mathrm{J} 5$ antiserum and the weak anti-J5 LPS antibody increase observed is that the factor responsible for the protection is a nonspecific polyclonal antibody increase rather than cross-protective anti-core LPS antibodies. Indeed, studies in rabbits suggest that a polyclonal response against $O$ antigens may occur after intravenous immunization with J5 bacteria [17]. However, the present data suggest that this is unlikely in man, because there was neither a significant increase in antibodies to LPS from smooth gram-negative bacteria nor an increase in the total IgG or IgM serum levels. Alternative explanations may be that $\mathrm{J} 5$ vaccine increased nonspecifically some unrecognized acute-phase reactants capable of neutralizing LPS, altering its metabolism, or counteracting the biologic effects of humoral or cellular factors released by the stimulation of LPS. Additional studies are needed to explore these possibilities.

\section{References}

1. Ziegler EJ, McCutchan JA, Fierer J, et al. Treatment of gram-negative bacteremia and shock with human antiserum to a mutant Escherichia coli. N Engl J Med 1982;307:1225-30.

2. Baumgartner JD, Glauser MP, McCutchan JA, et al. Prevention of gramnegative shock and death in surgical patients by prophylactic antibody to endotoxin core glycolipid. Lancet $1985 ; 2: 59-63$.

3. Jansson PE, Lindberg AA, Lindberg B, Wollin R. Structural studies on the hexose region of the core in lipopolysaccharides from entembacteraceae. Eur J Biochem 1981;115:571-7.

4. Heumann D, Baumgartner JD, Jacot-Guillarmod H, Glauser MP. Antibodies to core lipopolysaccharide determinants: absence of crossreactivity with heterologous lipopolysaccharides. J Infect Dis 1991; 163:762-8.

5. Ziegler EJ. Protective antibody to endotoxin core: the emperor's new clothes? [perspective]. J Infect Dis 1988;158:286-90.

6. Braude AI, Douglas H. Passive immunization against the local Shwartzman reaction. J Immunol 1972;108:505-12.

7. McCabe WR. Immunization with R mutants of $S$. minnesota. I. Protection against challenge with heterologous gram-negative bacilli. J Immunol 1972;108:601-10.

8. Ziegler EJ, Douglas H, Braude AI. Human antiserum for prevention of the local Shwartzman reaction and death from bacterial lipopolysaccharides. J Clin Invest 1973;52:3236-8.

9. Baumgartner JD, Glauser MP. Immunoprophylaxis and immunotherapy of gram-negative bacterial infections. In: Sissons P, Borysiewicz 
L, Cohen J, eds. Immunology of infection. Norwell, MA: Kluwer Academic Publishers, 1990

10. Dunn DL, Bogard WC, Cerra FB. Efficacy of type-specific and crossreactive murine monoclonal antibodies directed against endotoxin during experimental sepsis. Surgery 1985;98:283-9.

11. Teng NNH, Kaplan HS, Hebert JM. Protection against gram-negative bacteremia and endotoxemia with monoclonal IgM antibodies. Proc Natl Acad Sci USA 1985;82:1790-4.

12. Young LS, Gascon R, Alam S, Bermudez LE. Monoclonal antibodies for treatment of gram-negative infections. Rev Infect Dis 1989;11(suppl 7): $\$ 1564-71$

13. Pollack M, Chia JKS, Koles NL, Miller M, Guelde G. Specificity and cross-reactivity of monoclonal antibodies reactive with the core and lipid A regions of bacterial lipopolysaccharide. J Infect Dis 1989;159:168-88.
14. Baumgartner JD, Heumann D, Gerain J, Weinbreck P, Grau GE, Glauser MP. Association between protective efficacy of anti-lipopolysaccharide (LPS) antibodies and suppression of LPS-induced tumor necrosis factor $\alpha$ and interleukin 6: comparison of $O$ side chain-specific antibodies with core LPS antibodies. J Exp Med 1990;171:889-96.

15. Miner KM, Manyak CL, Williams E. Characterization of murine monoclonal antibodies to Escherichia coli J5. Infect Immun 1986;52:56-62.

16. Munford RS, Hall CL, Rick PD. Size heterogeneity of Salmonella typhimurium lipopolysaccharides in outer membranes and culture supernatant membrane fragments. J Bacteriol 1980;144:630-40.

17. Siber GR, Kania SA, Warren HS. Cross-reactivity of rabbit antibodies to lipopolysaccharide of Escherichia coli J5 and other gram-negative bacteria. J Infect Dis 1985;152:954-64. 